ИЗВЕСТИЯ АКАДЕМНИ НАУК ЭСТОНСКОИ ССР. ТОМ 25 ФИЗИКА * МАТЕМАТИКА. 1976, № 1

\title{
ИЗУЧЕНИЕ ВОДОРОДНОЙ СВЯЗИ ЭТИЛОВОГО ЭФИРА $N$-АЦЕТИЛГЛИЦИНА МЕТОДАМИ ИК И ЯМР СПЕКТРОСКОПИИ
}

Во вторичной структуре белков и ферментов, а также при стабилизации конформации у многих олигопептидов важную роль играют водородные связи типа $\mathrm{N}-\mathrm{H} . . \mathrm{O}=\mathrm{C}$. В соединениях с большим молекулярным весом детально изучить параметры Н-связи обычно трудно. Поэтому важно их изучение на различных модельных объектах с более низким молекулярным весом, например, на амидах и эфирах $N$-ацилированных аминокислот, дипептидах и т. д. Н-связь у амидов $N$-ацилированных аминокислот, имеющих две амидные связи, исследовалась многими авторами $\left[{ }^{1-9}\right]$. Меньше внимания обращалось на эфиры $N$-ацилированных аминокислот с одной амидной связью.

В настоящей работе изучалась Н-связь растворов этилового эфира $\mathrm{N}$-ацетилглицина (АГЭ) в $\mathrm{CCl}_{4}$ методами ИК и ЯМР спектроскопии.

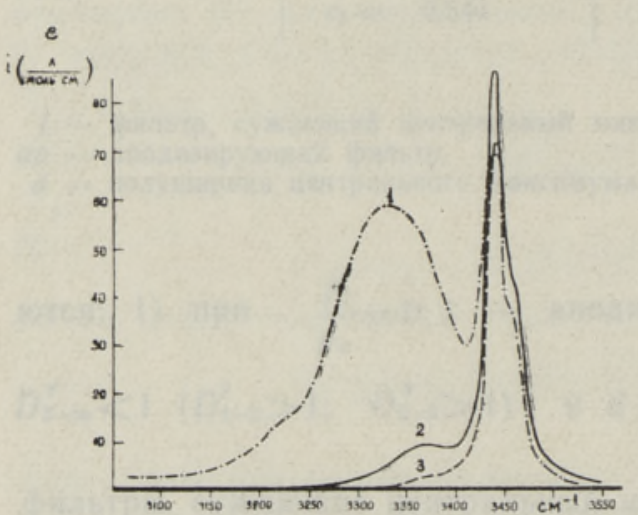

ИК спектры поглощения растворов АГЭ в $\mathrm{CCl}_{4}$ в области валентного колебания $\mathrm{N}-\mathrm{H}$ : $1-c=0,1 M, t=24^{\circ} \mathrm{C} ; 2-c=0,01 \mathrm{M}$, $t=24^{\circ} \mathrm{C} ; 3-c=0,005 \mathrm{M}, t=74^{\circ} \mathrm{C}$.
Для получения АГЭ глицин ацилировали ангидридом уксусной кислоты и после этого этерифицировали абсолютным этиловым спиртом при пропускании хлористого водорода $\left[{ }^{10}\right]$. Инфракрасные спектры растворов АГЭ в $\mathrm{CCl}_{4}$ в области $1600-1800$ и $3200-3500$ сM $^{-1}$ были сняты на спектрометре UR-20. Из рисунка видно, что полоса около 3330 $C M^{-1}$, соответствующая валентному колебанию водорода $\mathrm{NH}$, связанного водородным мостиком, при разбавлении растворов смещается в сторону больших волновых чисел, ее интенсивность уменьшается и она исчезает при концентрациях ниже $0,005 \mathrm{M}$. Такие изменения в инфракрасном спектре согласуются с данными работы $\left[{ }^{4}\right]$ и показывают, что АГЭ, в отличие от эфиров глицина $\left[{ }^{11}\right]$, образует только межмолекулярную $\mathrm{H}$-связь в растворе $\mathrm{CCl}_{4}$.

В молекуле АГЭ имеется три атома кислорода, которые, в принципе, все способны участвовать в образовании Н-связи. Важно установить, доминирует ли один из них в этом процессе или их роль сравнительно близка. 
В. А. Терентьевым сделан вывод, что атом кислорода карбонильной группы в сложных эфирах имеет гораздо бо́льшую электронодонорную способность, чем атом кислорода эфирной группировки в этой же молекуле, и конкуренция между этими двумя атомами всегда оканчивается в пользу карбонильного кислорода, поскольку константы образования Н-связи при сложных эфирах как донорах на порядок выше, чем при соответствующих простых эфирах $\left[{ }^{12}\right]$. В инфракрасном спектре растворов АГЭ в $\mathrm{CCl}_{4}$ полоса $1750 \mathrm{Cm}^{-1}$, соответствующая валентному колебанию $\mathrm{C}=\mathrm{O}$ сложноэфирной группы, является симметричной и узкой при концентрации $0,1 M$ и ниже. Это указывает на то, что соответствующий атом кислорода при этих концентрациях не участвует в образовании Н-связи или участвует в очень малой степени. Полоса $1694 \mathrm{~cm}^{-1}$ валентного колебания $\mathrm{C}=\mathrm{O}$ амидной группы асимметрична. На низкочастотной ветви этой полосы имеется ступенька, ширина которой уменьшается с повышением температуры и понижением концентрации. Существование такой ступеньки характерно для инфракрасной полосы $\mathrm{C}=\mathrm{O}$ группы, участвующей в образовании Н-связи.

В таблице приведены некоторые значения полуширин обеих ветвей полосы $1694 \mathrm{~cm}^{-1}$ в зависимости от концентрации и температуры. Из этих данных видно, что исчезновение разниц полуширин ветвей хорошо коррелируется с исчезновением полосы валентного колебания водорода $\mathrm{NH}$, связанного водородным мостиком (см. рисунок). Это совпадение также подтверждает участие амидной группы в образовании Н-связи.

На основе вышесказанного можно сделать вывод, что из трех атомов кислорода в АГЭ самой сильной электронодонорной способностью обладает амидный кислород и в растворах $\mathrm{AГӘ} \mathrm{в} \mathrm{CCl}_{4}$ доминирует равновесие<smiles>CCOC(=O)CNC(C)=O</smiles>

Так как в основном нами исследовались разбавленные растворы, где преобладает равновесие мономер-димер, образование высших ассоциатов здесь не рассматривается.

Зависимость полуширины ветвей полосы валентного колебания $\mathrm{C}=\mathrm{O}$ амидной группы (1694 $\left.\mathrm{CM}^{-1}\right)$ от концентрации и температуры растворов АГЭ в $\mathrm{CCl}_{4}$

\begin{tabular}{c|c|c|c}
\hline $\begin{array}{c}\text { Концентрация } \\
\text { раствора, } \\
\text { моль/ }\end{array}$ & Температура, & $\begin{array}{c}\text { Полуширина } \\
\text { низкочастотной } \\
\text { ветви, } c M^{-1}\end{array}$ & $\begin{array}{c}\text { Полуширина } \\
\text { высокочастотной } \\
\text { ветви, } c M^{-1}\end{array}$ \\
\hline
\end{tabular}

$\begin{array}{llll}0,1 & 24 & 24 & 12 \\ 0,05 & 24 & 17 & 12 \\ 0,05 & 70 & 15 & 12 \\ 0,005 & 25 & 11 & 11\end{array}$


Энтальпия образования Н-связи определялась из результатов измерения спектров ЯMP. ${ }^{1} \mathrm{H}$, которые были сняты на спектрометре TESLA BS487C при частоте 80 Мгц. Химический сдвиг измерялся с точностью 0,005 м. д. Внутренним стандартом служил циклогексан. Заданная температура поддерживалась в пробе с точностью $\pm 2{ }^{\circ} \mathrm{C}$. Измерения проводились при каждой концентрации на трех образцах, полученных разбавлением разных исходных растворов. Резонансный сигнал протонов NH в ЯМР спектре расширен вследствие влияния ядер азота ${ }^{14} \mathrm{~N}$, имеющих квадрупольный момент. Для получения их узкого сигнала использовался $\left\{{ }^{14} \mathrm{~N}\right\}^{1} \mathrm{H}$ двойной резонанс, аналогично работе $\left[{ }^{13}\right]$.

Кроме ассоциативных процессов, на температурную зависимость химического сдвига может влиять также цис-транс-изомерия пептидной связи $\left[{ }^{14,15}\right]$. Но учитывая, что температуры коалесценции сигналов двух изомерных форм в пептидах и амидах остаются в пределах

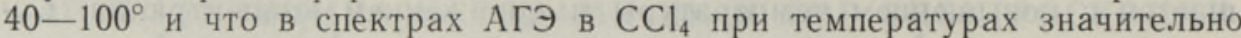
ниже вышеуказанных $\left(-10^{\circ}\right)$ сигналы двух изомерных форм обнаружить не удалось, можно предполагать, что АГЭ существует в основном в одной, энергетически более выгодной $\left[{ }^{16}\right]$ транс-конфигурации.

Для определения энтальпии образования Н-связи измерялся химиче-

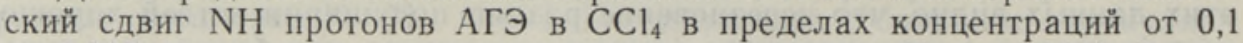
до $0,005 M$ при восьми разных температурах от $+2^{\circ}$ до $+100^{\circ}$. Значения химического сдвига $\delta_{0}$ при нулевой концентрации находили экстраполяцией, используя для этой цели участок кривой зависимости $\delta, c$ начиная с содержания АГЭ в растворе ниже $0,03 \mathrm{M}$, поскольку при этих концентрациях зависимость $\delta_{0}$ от $c$ близка к линейной. Измерить химический сдвиг протонов NH до столь малых концентраций обычно не удается $\left[{ }^{17,18}\right]$ из-за их широкого сигнала и поэтому экстраполяционную величину $\delta_{0}$ в этих работах нельзя считать достоверной. Полученные нами значения $\delta_{0}$ несколько уменьшаются с повышением температуры. Аналогичное явление наблюдали Т. Грамстад и Е. Д. Бекер у растворов фенола в $\mathrm{CCl}_{4}$ и циклогексане $\left[{ }^{19}\right]$. Зависимость химического сдвига $\delta_{0}$ от температуры может быть обусловлена образованием слабой $\mathrm{H}$ связи между водородом $\mathrm{NH}$ и $\mathrm{CCl}_{4}\left[{ }^{20,21}\right]$ или наличием остатков воды в растворителе.

Энтальпию образования Н-связи можно вычислить из результатов измерения химического сдвига при помощи уравнения работы $\left[{ }^{22}\right]$

$$
-\Delta H=R \frac{\partial \ln \left(\frac{\partial \delta}{\partial x_{0}}\right)_{x_{\triangleleft} \rightarrow 0}}{\partial \frac{1}{T}},
$$

где $x_{0}$ - концентрация раствора; $T$ - абсолютная температура.

На основе углового коэффициента прямой $\log \left(\frac{\partial \delta}{\partial x_{0}}\right)_{x_{0} \rightarrow 0} 1 / T$ вычисленное значение $\Delta \mathrm{H}=-4,4 \kappa \kappa a л /$ моль. Это значение довольно хорошо

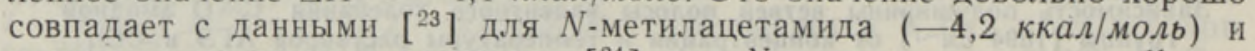
несколько превышает результат $\left[{ }^{24}\right]$ для $N$-метиламида ацетил- $d l$-норлейцина $\left(-3,9 \kappa \kappa a л /\right.$ моль). В работах $\left[{ }^{23,24}\right]$ значения $\Delta H$ получены из ИК измерений четыреххлористых растворов.

\section{Выводы}

1. Установлено, что этиловый эфир $\mathrm{N}$-ацетилглицина (АГЭ) в $\mathrm{CCl}_{4}$ образует в основном только межмолекулярную Н-связь между водородом NH и амидным кислородом. 
2. Энтальпия образования $\mathrm{H}$-связи АГЭ в $\mathrm{CCl}_{4}$, рассчитанная на

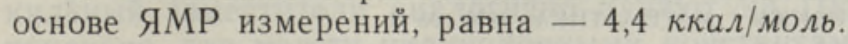

\section{Л И ТЕРА Т Р А}

1. Mizushima S., Shimanouchi T., Tsuboi M., Sugita T, Kato E., Ko n d o E., J. Amer. Chem. Soc., 73, 1330 (1951).

2. Mizushima S., Shimanouchi T., Tsuboi M., Souda R., J. Amer. Chem. Soc., 74, 270 (1952).

3. Mizushima S., Shimanouchi T, Tsuboi M., Sugita T, Kuro Saki K., M at a g a N., S oud a R., J. Amer. Chem. Soc., 74, 4639 (1952).

4. Mizushima S., Shimanouchi T., Tsuboi M., Kuratani K., Sugit a T., M a tag a N., S o ud a R., J. Amer. Chem. Soc., 75, 1863 (1953).

5. Mizushima S., Tsuboi M., Shimanouchi T., Sugita T., Yoshim o t o T., J. Amer. Chem, Soc., 76, 2479 (1954).

6. Mizushima S., Shimanouchi T., Tsuboi M., Arakawa T., J. Amer. Chem. Soc., 79, 5357 (1957).

7. Tsuboi M., Shimanouchi T., Mizushima S., J. Amer. Chem. Soc., 81, $1406(1959)$

8. Е фремов Е. С., Сенявина Л. Б., Желтова В. Н., Иванова А. Г., Косецкий П. В., Ив анов В. Т., Попов Е. М., Овчинников Ю. А., Химия прир. соед., 9, 322 (1973).

9. Avignon M., Huong P. V., Laskombe J., Biopolymers, 8, 69 (1969).

10. R a de $\mathrm{nh}$ a usen R., J. prakt. Chem., 52, 437 (1895).

11. Билоброва А. И,, Ша ринин Ю. А., Литвиненко Л. М., Титов Е. В. Бе ло бров В. М., Реакц. способн. орг. соед., 9, 655 (1972).

12. Т е ре н тьев В. А., Термодинамика водородной связи, Саратов, 1973.

13. L i p p m a E., All a M., ENSV TA Toimet., Füüs. Matem., 15, 620 (1966)

14. Stewart W. E., Sidd all T. H., Chem. Rev., 70, 517 (1970).

15. Портнова С. Л., Быстров В. Ф., Балашова Т. А, Иванов В. Т., О в чинников Ю. А., Изв. АН СССР, сер. хим., $825(1970)$.

16. R a m a chandran G. N., S a s is ekh a ra n V., Adv. Prot. Chem., 23, 283 (1968).

17. La Planche L. A., Thompson H. B., Rogers M. T., J. Phys. Chem., 69, 1482 (1965).

18. H a p p e J. A., J. Phys. Chem., 65, 72 (1961).

19. Gramst ad T., Becker E. D., J. Molec. Struct., 5, 253 (1970).

20. Jumper C. F., Emerson M. T., Howard B. B., J. Chem. Phys., 35, 1911 (1961).

21. D ix s o n W. B., J. Phys. Chem., 74, 1396 (1970).

22. D a vis J. C., P itzer K. S., R a o C. N. R., J. Phys. Chem., 64, 1744 (1960).

23. Klotz I. K., Franzen J. S., J. Amer. Chem. Soc., 84, 3461 (1961).

24. T s u b o i M., J. Chem. Soc. Japan, 76, 380 (1955).

Ннститут термофизики и электрофизики Академии наук Эстонской ССР

\section{Поступила в редакцию} 14/III 1975

\section{SLET, H. SALANDI, T. LUMISTE, I. ARRO}

\section{N-ATSETUOLGLUTSIINI ETUOLESTRI VESINIKSIDEME UURIMINE TUUMAMAGNETRESONANTS- JA INFRAPUNASE SPEKTROSKOOPIA ABIL}

Uuriti $N$-atsetüülglütsiini etüülestri vesiniksidet lahjades $\mathrm{CCl}_{4}$ lahustes $(0,1-0,005 \mathrm{M})$. Leiti, et $N$-atsetüülglütsiini etüülester moodustab molekulidevahelise vesiniksideme pöhiliselt NH-rühma vesiniku ja amiidse hapniku vahel, kusjuures vesiniksideme moodustumise entalpia väärtus on $-4,4 \mathrm{kcal} / \mathrm{mool}$.

\section{SLET, H. SALANDI, T. LUMISTE, I. ARRO}

\section{THE STUDY OF THE HYDROGEN BOND OF $N$-ACETYLGLYCINE ETHYL ESTER BY NMR AND IR SPECTROSCOPY METHODS}

The $\mathrm{H}$-bond of $\mathrm{N}$-acetylglycine ethyl ester in carbon tetrachloride solution was studied by NMR and IR spectroscopy methods. It was found that $\mathrm{N}$-acetylglycine ethyl ester forms an intramolecular H-bond mainly between the NH-hydrogen and amide oxygen, and the value of the enthalpy of formation of that $\mathrm{H}$-bond is $-4.4 \mathrm{kcal} / \mathrm{mole}$. 